\title{
Impact of type 2 diabetes mellitus on hospitalization costs in older patients with acute myocardial infarction
}

\author{
Kai-li Fu' \\ Guan-qi Fan' \\ Lu Han' \\ Xiao-zhen Wang ${ }^{2}$ \\ Jia Wang' \\ Yu-shu Wang' \\ Ming Zhong' \\ Yun Zhang' \\ Wei Zhang' \\ Zhi-hao Wang ${ }^{3}$ \\ 'Key Laboratory of Cardiovascular \\ Remodeling and Function Research, \\ Chinese Ministry of Education and \\ Chinese Ministry of Public Health, \\ and Department of Cardiology, Qilu \\ Hospital of Shandong University, \\ ${ }^{2}$ Shandong University of Traditional \\ Chinese Medicine, ${ }^{3}$ Department of \\ Geriatric Medicine, Qilu Hospital of \\ Shandong University, Ji'nan, People's \\ Republic of China
}

This article was published in the following Dove Press journal:

Clinical Interventions in Aging

25 April 2014

Number of times this article has been viewed
Background: The purpose of this study was to evaluate the impact of type 2 diabetes mellitus on hospitalization costs in older patients with acute myocardial infarction (MI).

Methods: Retrospective analysis of data from the case retrieval system of Qilu Hospital of Shandong University located in Jinan city of Shandong Province was done for patients with acute MI from January 1, 2011 to December 31, 2012.

Results: Stenting was an important factor affecting older patients' total hospitalization costs ( $\beta=0.685, P=0.000$ ) and treatment costs during the follow-up period (duration of hospital stay only, $\beta=0.508, P=0.000$ ). Stenting was also a protective factor in the prevention of acute heart failure (HF) in older patients with acute MI during the follow-up period (odds ratio 0.189, $95 \%$ confidence interval $0.059-0.602, P=0.005$ ). Implementation of percutaneous coronary intervention reduced the incidence of acute HF in older inpatients with acute MI (27.8\% versus $4.3 \%, P=0.001)$ and without diabetes $(18.2 \%$ versus $3.8 \%, P=0.001)$. Moreover, among the elderly, the incremental cost-effectiveness ratio estimate for implementing percutaneous coronary intervention in diabetic patients was higher than in nondiabetic patients.

Conclusion: Stenting was a protective factor for preventing acute HF in the elderly during the follow-up period. From the perspective of reducing the incidence of acute HF in inpatients, implementation of percutaneous coronary intervention after an acute MI is more cost-effective in older patients with diabetes mellitus than in those without it.

Keywords: diabetes, aging, myocardial infarction, hospitalization costs, vascular

\section{Introduction}

The People's Republic of China has become a country with an aging population, which is growing rapidly and will peak by the middle of this century. ${ }^{1,2}$ Changes in the age structure of the population will have a major impact on the overall health of this country and its health care system.

In the People's Republic of China and throughout the rest of the world, the high prevalence of acute myocardial infarction (MI) places an enormous economic burden upon societies, and the largest component of medical expenditure is inpatient hospital care. ${ }^{3-6}$ Despite a significant reduction in mortality rates associated with cardiovascular disease in the era of percutaneous coronary intervention (PCI), acute MI continues to be a leading cause of hospital admission and death in older adults, ${ }^{7,8}$ because the risk of acute MI increases with age. ${ }^{9}$

Diabetes mellitus is a growing national epidemic ${ }^{10-12}$ and is an independent predictor of mortality in patients with acute MI. ${ }^{13-17}$ The incidence of diabetes in patients with acute MI is already showing a gradual upward trend. ${ }^{18-20}$ 
The prevalence of diabetes increases with age. ${ }^{21-23}$ Age is an important determinant of care in patients with acute $\mathrm{MI}$, with older patients receiving treatment less often than their younger counterparts ${ }^{24-26}$ and those aged 65 years and older having a higher mortality risk than younger patients after PCI for acute MI. ${ }^{27}$ However, Nicolau et al estimated that hyperglycemia in patients with acute MI is a better predictor of mortality in younger patients than in the elderly population. ${ }^{28}$ Previous studies have shown that primary PCI can reduce both early and late adverse events in diabetic patients with acute $\mathrm{MI},{ }^{29}$ and diabetics hospitalized for acute MI incur more costs than nondiabetics. ${ }^{19,30}$ However, no data are currently available for the role of diabetes in the outcome of PCI and hospitalization costs in older inpatients with acute MI.
Older diabetics have a two-fold increased risk of dying from acute MI. However, few studies to date have examined the relationship between hospitalization costs, clinical treatment, and prognosis. The aim of this study was to evaluate the impact of type 2 diabetes mellitus on hospitalization costs in older patients with acute MI. The aging population of the People's Republic of China is growing rapidly, and older populations have an increased need for primary care. Therefore, it is important to be able to estimate the impact of diabetes on hospitalization costs in older patients with acute $\mathrm{MI}$, and increase public awareness of the issues involved in taking care of the elderly. Our study data may be helpful for clinicians when devising appropriate treatment strategies and may also assist policy-makers in making informed decisions about future health policy and budgets.

Table I Summary of patients' demographic and clinical characteristics

\begin{tabular}{|c|c|c|c|c|c|}
\hline & $\begin{array}{l}Y+\text { nondiabetic } \\
(n=256)\end{array}$ & $\begin{array}{l}O+\text { nondiabetic } \\
(n=227)\end{array}$ & $\begin{array}{l}Y+\text { diabetic } \\
(n=\mid 13)\end{array}$ & $\begin{array}{l}\text { O+ diabetic } \\
(n=137)\end{array}$ & $P$-value \\
\hline Male, n (\%) & $228(89.1)$ & $132(58.1)^{*}$ & $87(76.1)^{*, \#}$ & $7 \mid(5 \mid .8)^{*, \Delta}$ & 0.000 \\
\hline Age (years) & $53.03 \pm 8.73$ & $74.84 \pm 6.47^{*}$ & $55.77 \pm 7.03^{* \#}$ & $74.77 \pm 5.66^{*, \Delta}$ & 0.000 \\
\hline Height $(\mathrm{cm})$ & $170.23 \pm 6.72$ & $166.51 \pm 7.35^{*}$ & $169.34 \pm 6.96^{\#}$ & $165.15 \pm 7.22^{*, \Delta}$ & 0.000 \\
\hline Weight (kg) & $74.31 \pm 12.18$ & $67.30 \pm 12.18^{*}$ & $76.46 \pm 11.02^{\#}$ & $67.31 \pm 11.20^{*, \Delta}$ & 0.000 \\
\hline BMI $\left(k g / m^{2}\right)$ & $25.56 \pm 3.45$ & $24.20 \pm 3.72 *$ & $26.60 \pm 2.89 * \#$ & $24.53 \pm 3.65^{*, \Delta}$ & 0.000 \\
\hline $\mathrm{SBP}(\mathrm{mmHg})$ & $123.78 \pm 18.94$ & $131.69 \pm 22.78^{*}$ & $130.54 \pm 25.02 *$ & $|38.29 \pm 2| .85^{* \#, \Delta}$ & 0.000 \\
\hline $\mathrm{DBP}(\mathrm{mmHg})$ & $75.09 \pm 13.42$ & $75.20 \pm 12.98$ & $77.54 \pm 15.63$ & $75.99 \pm 11.95$ & 0.390 \\
\hline HR (per minute) & $74.04 \pm|3.5|$ & $78.24 \pm 18.10^{*}$ & $79.72 \pm|4.6|^{*}$ & $81.44 \pm 17.75^{*}$ & 0.000 \\
\hline Cholesterol (mmol/L) & $4.46 \pm 1.15$ & $22.95 \pm 272.05$ & $4.65 \pm 1.13$ & $4.65 \pm 1.15$ & 0.520 \\
\hline $\mathrm{TG}(\mathrm{mmol} / \mathrm{L})$ & $1.72 \pm 1.39$ & $1.30 \pm 0.77 *$ & $1.82 \pm 0.74^{\#}$ & $1.45 \pm 0.79^{*, \Delta}$ & 0.000 \\
\hline $\mathrm{HDL}(\mathrm{mmol} / \mathrm{L})$ & $1.08 \pm 0.25$ & $1.19 \pm 0.25^{*}$ & $1.0 \mathrm{I} \pm 0.2 \mathrm{I}^{\text {*\#\# }}$ & $1.12 \pm 0.26^{\#, \Delta}$ & 0.000 \\
\hline LDL (mmol/L) & $3.00 \pm 3.85$ & $2.84 \pm 0.81$ & $2.99 \pm 0.92$ & $2.90 \pm 0.90$ & 0.888 \\
\hline WBC (109/L) & $8.56 \pm 2.99$ & $34.84 \pm 403.08$ & $9.36 \pm 10.25$ & $8.00 \pm 3.09$ & 0.553 \\
\hline $\operatorname{RBC}\left(10^{12} / \mathrm{L}\right)$ & $4.34 \pm 0.52$ & $4.04 \pm 0.63 *$ & $4.28 \pm 0.63^{\#}$ & $3.88 \pm\left. 0.6\right|^{*, \#, \Delta}$ & 0.000 \\
\hline $\mathrm{Hb}\left(10^{2} \mathrm{~g} / \mathrm{L}\right)$ & $139.45 \pm 15.19$ & $|27.9| \pm 19.36^{*}$ & $135.16 \pm 20.87^{*, \#}$ & $124.07 \pm 22.38$ & 0.000 \\
\hline PLT (10'1/L) & $207.96 \pm 56.72$ & $204.28 \pm 88.87$ & $209.17 \pm 66.20$ & $199.53 \pm 84.42$ & 0.694 \\
\hline FIB $(g / L)$ & $3.69 \pm 1.20$ & $3.62 \pm 0.99$ & $4.01 \pm 1.52^{* \# \#}$ & $3.78 \pm 1.06$ & 0.037 \\
\hline $\mathrm{UA}(\mu \mathrm{mol} / \mathrm{L})$ & $316.12 \pm 89.45$ & $304.23 \pm 109.81$ & $311.92 \pm 85.49$ & $319.90 \pm 118.01$ & 0.477 \\
\hline Stenting, n (\%) & $211(82.4)$ & $106(46.7)^{*}$ & $74(65.5)^{*, \#}$ & $47(34.3)^{* \#, \Delta}$ & 0.000 \\
\hline Insulin, n (\%) & 0 & 0 & $39(34.5)$ & $57(4 I .6)$ & \\
\hline Sulfonylureas, n (\%) & 0 & 0 & $34(30.1)$ & 27 (19.7) & \\
\hline Glinide, n (\%) & 0 & 0 & $8(7.1)$ & II (8.0) & \\
\hline Biguanides, n (\%) & 0 & 0 & $56(50.4)$ & $42(30.7)^{\Delta}$ & \\
\hline Glitazones, n (\%) & 0 & 0 & $3(2.7)$ & $3(2.2)$ & \\
\hline Acarbose, n (\%) & 0 & 0 & $29(25.7)$ & $39(28.5)$ & \\
\hline Nitrate esters, n (\%) & $205(80.1)$ & I 98 (87.2)* & $102(90.3)^{*}$ & $130(94.9)^{*, \#}$ & 0.000 \\
\hline Diuretics, n (\%) & $30(11.7)$ & $79(34.8)^{*}$ & $31(27.4)^{*}$ & $58(42.3)^{*, \Delta}$ & 0.000 \\
\hline CCB, n (\%) & $49(19.1)$ & $59(26.0)$ & $34(30.1)^{*}$ & $50(36.5)^{*, \#}$ & 0.002 \\
\hline$\beta$-blockers, n (\%) & $183(7 \mid .5)$ & 157 (69.2) & $78(69.0)$ & $80(58.4)^{*, \#}$ & 0.060 \\
\hline ACEI, n (\%) & 9I (35.5) & 81 (35.7) & $39(34.5)$ & $39(28.5)$ & 0.487 \\
\hline ARB, n (\%) & $74(28.9)$ & 7I (3I.3) & $34(30.1)$ & $44(32.1)$ & 0.908 \\
\hline Acetylsalicylic acid, n (\%) & $255(99.6)$ & $219(96.5)^{*}$ & $109(96.5)^{*}$ & I 35 (98.5) & 0.058 \\
\hline
\end{tabular}

Notes: Group $Y$, aged $<65$ years; group $O$, aged $\geq 65$ years; ${ }^{*} P<0.05$ versus $Y+$ nondiabetic; ${ }^{\#}<0.05$ versus $O+$ nondiabetic; ${ }^{\Delta P}<0.05$ versus $Y+$ diabetic.

Abbreviations: BMI, body mass index; SBP, systolic blood pressure; DBP, diastolic blood pressure; HR, heart rate; TG, triglycerides; HDL, high-density lipoprotein cholesterol; LDL, low-density lipoprotein cholesterol; WBC, white cell count; RBC, red cell count; Hb, hemoglobin; PLT, platelets; FIB, fibrinogen; UA, uric acid; CCB, calcium channel blockers; ACEl, angiotensin-converting enzyme inhibitors; ARB, angiotensin receptor blockers. 
Table 2 Comparison of hospitalization costs and hospital stay between diabetic and nondiabetic patients

\begin{tabular}{|c|c|c|c|}
\hline & $\begin{array}{l}\text { Nondiabetes } \\
(n=483)\end{array}$ & $\begin{array}{l}\text { Diabetes } \\
(n=250)\end{array}$ & $P$-value \\
\hline Total costs $(\$)$ & $\begin{array}{l}8,814 \\
(4,703-11,835)^{*}\end{array}$ & $\begin{array}{l}7,171 \\
(3,328-11,084)\end{array}$ & 0.006 \\
\hline Treatment costs $(\$)$ & $\begin{array}{l}|,| 7 \mid \\
(79 \mid-5,979)\end{array}$ & $\begin{array}{l}975 \\
(400-1,844)\end{array}$ & 0.000 \\
\hline Hospital stay (days) & II (8-I4) & $12(9-15)$ & 0.017 \\
\hline
\end{tabular}

Notes: Costs are in US dollars. *Median (interquartile range).

\section{Materials and methods Study design and data source}

Data from the case retrieval system at Qilu Hospital of Shandong University were used. This was a retrospective study of all consecutive patients admitted to Qilu Hospital of Shandong University with a diagnosis of acute MI from January 1, 2011 to December 31, 2012.

\section{Study population}

The diagnostic criteria for acute MI included chest pain lasting 20 minutes or more that was not relieved by nitrates, electrocardiographic changes suggestive of evolving MI, and a subsequent increase in cardiac enzyme levels to more than twice the upper limit of normal. Patients with acute MI and aged 26-97 years were identified from the case retrieval system data. The following inclusion criteria were used: acute MI explicitly included in the discharge diagnosis; a discharge diagnosis of acute coronary syndrome (including acute MI and unstable angina) and cardiac troponin I $>0.06 \mathrm{ng} / \mathrm{mL}$; and emergency PCI. Patients with type 2 diabetes mellitus were identified by diagnosis at discharge. The study subjects were divided into two age groups, ie, $<65$ years and $\geq 65$ years. A total of 113 younger diabetic patients, 256 younger nondiabetic patients, 137 older diabetic patients, and 227 older nondiabetic patients were included. Patients who electively interrupted treatment in hospital were excluded.

\section{Definition of variables}

Forty-seven variables in the case retrieval system data were defined for this study. Patient demographic characteristics, laboratory test results, coronary angiography results, whether or not a stent was implanted, drug use during hospitalization, cardiovascular events during the follow-up period (duration of hospital stay only) including acute heart failure (HF) were defined according to records which showed that patients suffered from acute HF, atrial arrhythmia, ventricular arrhythmia, secondary revascularization, rescue, and death. Hospitalization costs over the follow-up period, including total hospitalization costs, treatment costs (including custody fee, rescue fee, interventional treatment costs), total drug costs, laboratory testing fees, inspection fees, consultation fees, bed fees, and nursing fees were defined. Categorical variables were assigned 1 or 0 according to whether present or absent.

\section{Statistical analysis}

Statistical Package for the Social Sciences version 17.0 software (IBM Corporation, Armonk, NY, USA) was used for the data analysis. Continuous variables were expressed as the mean \pm standard deviation and categorical variables were expressed as frequencies. One-way analysis of variance was used to compare the means of four samples. The relationship between qualitative variables was evaluated using the $\chi^{2}$ test or Fisher's exact test. The results were considered to be statistically significant at a $P$-value of $<0.05$. A univariate general linear model was used to estimate the interaction between diabetes, stenting, and hospitalization costs. To identify factors possibly predictive of hospitalization costs, we constructed multiple linear regression models in which hospitalization costs were considered to be dependent variables and the others as independent variables. The stepwise variable selection method was used for all analysis. The results are presented with regression coefficients and

Table 3 Comparison of hospitalization costs and hospital stay among different groups

\begin{tabular}{|c|c|c|c|c|c|}
\hline & $\begin{array}{l}Y+\text { nondiabetic } \\
(n=256)\end{array}$ & $\begin{array}{l}O+\text { nondiabetic } \\
(n=227)\end{array}$ & $\begin{array}{l}Y+\text { diabetic } \\
(n=|| 3)\end{array}$ & $\begin{array}{l}\text { O + diabetic } \\
(n=137)\end{array}$ & $P$-value \\
\hline Total costs $(\$)$ & $9,74 I \pm 4,568$ & $7,879 \pm 5,417^{*}$ & $8,761 \pm 4,946$ & $6,916 \pm 5,038^{*, \Delta}$ & 0.000 \\
\hline Treatment costs $(\$)$ & $4,339 \pm 4,746$ & $2,783 \pm 4,239 *$ & $3,452 \pm 4,449$ & $1,899 \pm 3,264^{*, \Delta}$ & 0.000 \\
\hline Total drug costs $(\$)$ & $2,093 \pm 1,273$ & $2,467 \pm I, 687^{*}$ & $2,259 \pm 1,332$ & $2,559 \pm I, 503^{*}$ & 0.007 \\
\hline Laboratory testing fees $(\$)$ & $259 \pm 118$ & $334 \pm 213^{*}$ & $314 \pm 166 *$ & $385 \pm 220^{* * \#, \Delta}$ & 0.000 \\
\hline Inspection fees $(\$)$ & $62 \pm 75$ & $78 \pm 80$ & $65 \pm 64$ & $91 \pm 153^{*, \Delta}$ & 0.023 \\
\hline Consultation fees $(\$)$ & $6.5 \pm 4.3$ & $9.0 \pm 6.8^{*}$ & $8.5 \pm 7.2 *$ & $10.2 \pm 7.5^{*, \Delta}$ & 0.000 \\
\hline Bed fees $(\$)$ & $92 \pm 103$ & $159 \pm 208 *$ & || $5 \pm|4|^{\#}$ & $173 \pm 203^{*, \Delta}$ & 0.000 \\
\hline Nursing fees (\$) & $16.5 \pm 20.2$ & $31.5 \pm 76.7^{*}$ & $18.8 \pm 36.2^{\#}$ & $24.7 \pm 39.7$ & 0.007 \\
\hline Hospital stay (days) & $10.7 \pm 5.9$ & $12.7 \pm 6.3 *$ & $1 \mathrm{I} .4 \pm 5.5$ & $13.5 \pm 6.7^{*, \Delta}$ & 0.000 \\
\hline
\end{tabular}

Notes: Costs are in US dollars. Group $Y$, aged $<65$ years; group $O$, aged $\geq 65$ years; ${ }^{*} P<0.05$ versus $Y+$ nondiabetic; ${ }^{*} P<0.05$ versus $O+$ nondiabetic; $\Delta P<0.05$ versus $Y+$ diabetic. 
Table 4 Multivariate linear regression model of factors affecting total costs and treatment costs for older patients with acute myocardial infarction

\begin{tabular}{llll}
\hline & $\boldsymbol{\beta}$ & $\boldsymbol{R}^{2}$ & $P$-value \\
\hline Total costs & & & \\
$\quad$ Stent $(\mathrm{Y} / \mathrm{N})$ & 0.685 & 0.514 & 0.000 \\
White cell count (I09/L) & 0.152 & 0.530 & 0.000 \\
Secondary revascularization & 0.130 & 0.550 & 0.003 \\
$\quad(\mathrm{Y} / \mathrm{N})$ & & & \\
Atrial arrhythmia (Y/N) & 0.116 & 0.566 & 0.006 \\
$\quad$ Weight (kg) & 0.109 & 0.583 & 0.011 \\
Treatment costs & & & \\
$\quad$ Stent $(\mathrm{Y} / \mathrm{N})$ & 0.508 & 0.289 & 0.000 \\
Fibrinogen (g/L) & 0.176 & 0.312 & 0.000 \\
$\quad$ Twice vascular & 0.145 & 0.330 & 0.002 \\
$\quad$ reconstruction $(\mathrm{Y} / \mathrm{N})$ & & & \\
\hline
\end{tabular}

$P$-values. In linear regression, the regression coefficient represents the increase in the response variable produced by a one-unit increase in the predictor variable associated with that coefficient. The value of the coefficient of determination, $R^{2}$, is also reported for each of the fitted models. A binary logistic regression model was used to identify factors affecting the incidence of acute HF.

\section{Cost-effectiveness analysis}

A cost-effectiveness analysis was included in this study as an effectiveness measure to compare the value of different interventions across acute MI patients in terms of avoiding cardiovascular events. Cost-effectiveness ratio (CER), which is a measure of the incidence of cardiovascular events per average costs in this study, was calculated for the four groups. Incremental cost-effectiveness ratio (ICER), which is expressed as difference in incidence of cardiovascular events between diabetics and nondiabetics, was calculated to compare diabetics and nondiabetics implemented PCI with regard to both costs and effects. They are defined as:

$$
\mathrm{CER}=\frac{\mathrm{P}}{\mathrm{C}}
$$

$$
\operatorname{ICER}=\frac{\Delta \mathrm{P}}{\Delta \mathrm{C}}=\frac{\mathrm{P}_{1}-\mathrm{P}_{0}}{\mathrm{C}_{1}-\mathrm{C}_{0}}
$$

where $\mathrm{P}$ is the inpatient incidence of cardiovascular events, $\mathrm{C}$ is average hospitalization cost, $\Delta \mathrm{P}$ is the difference in inpatient incidence of cardiovascular events between different interventions, $\Delta \mathrm{C}$ is the difference in costs between each intervention, $\mathrm{P}_{1}$ and $\mathrm{P}_{0}$ are the inpatient incidence of cardiovascular events, and $\mathrm{C}_{1}$ and $\mathrm{C}_{0}$ are average hospitalization costs.

\section{Results}

In total, 733 hospitalizations due to acute MI were identified, comprising 250 patients with diabetes and 483 without diabetes. We retrospectively evaluated 137 older patients with diabetes (mean age $74.77 \pm 5.66$ years, $71 \mathrm{men}$ ), 113 younger patients with diabetes (mean age $55.77 \pm 7.03$ years, 87 men), 227 older patients without diabetes (mean age $74.84 \pm 6.47$ years, 132 men), and 256 younger patients without diabetes (mean age $53.03 \pm 8.73$ years, $228 \mathrm{men}$ ). In younger patients with acute MI, those with diabetes were older than those without diabetes $(P<0.05)$, and nondiabetic patients were predominantly male $(89.1 \%$ versus $76.1 \%$ for those with diabetes; $P<0.05)$. For older patients, there was no significant difference in gender composition between diabetic and nondiabetic patients $(P>0.05)$. For the four groups, there was no difference in diastolic blood pressure, cholesterol, low-density lipoprotein cholesterol, white cell count, platelet count, or uric acid, or in the use of $\beta$-blockers, angiotensin-converting enzyme inhibitors, angiotensin receptor blockers, or acetylsalicylic acid $(P>0.05)$. Height, weight, body mass index, systolic blood pressure, heart rate, triglycerides, high-density lipoprotein cholesterol, red cell count, hemoglobin, fibrinogen, incidence of PCI, and there was difference in use of nitrate esters, diuretics, and calcium channel blockers among the four groups $(P<0.05$, Table 1). Total hospitalization costs and treatment costs were lower for diabetic patients than for nondiabetic patients $(P<0.05)$, but mean duration of hospital stay was longer for diabetics than for nondiabetics $(P<0.05$,

Table 5 Interaction between diabetes and stent and its effect on hospitalization costs and hospital stay in older patients with myocardial

\begin{tabular}{|c|c|c|c|c|c|c|c|}
\hline & $\begin{array}{l}\text { Diabetes } \\
(n=90)\end{array}$ & $\begin{array}{l}\text { No diabetes } \\
(n=|2|)\end{array}$ & $\begin{array}{l}\text { Diabetes + stent } \\
(n=47)\end{array}$ & $\begin{array}{l}\text { No diabetes + stent } \\
(n=106)\end{array}$ & $\boldsymbol{P}_{1}$ & $P_{2}$ & $P_{0}$ \\
\hline Total costs $(¥)$ & $37,169 \pm 22,233$ & $40,090 \pm 25,577$ & $81,447 \pm 26,042$ & $81,494 \pm 29,060$ & 0.958 & 0.000 & 0.907 \\
\hline Treatment costs ( $¥)$ & $5,6 \mid 2 \pm 7,197$ & $6,223 \pm 4,923$ & $30,017 \pm 30,273$ & $37,657 \pm 35,426$ & 0.224 & 0.000 & 0.028 \\
\hline Total drug costs $(¥)$ & $8,647 \pm 7,354$ & $9,114 \pm 5,795$ & $32,4 \mid 6 \pm 30,300$ & $39,602 \pm 35,167$ & 0.596 & $0.77 \mid$ & 0.750 \\
\hline Laboratory testing fees $(¥)$ & $2,855 \pm I, 682$ & $2,89| \pm I, 5| 8$ & $2,399 \pm 1,316$ & $\mathrm{I}, 945 \pm \mathrm{I}, 537$ & 0.032 & 0.093 & 0.308 \\
\hline Hospital stay (days) & $14.02 \pm 5.88$ & $13.72 \pm 6.75$ & $|2.5| \pm 5.88$ & $11.57 \pm 5.44$ & 0.382 & 0.011 & 0.653 \\
\hline
\end{tabular}
infarction

Notes: $P_{1}$, diabetes versus no diabetes; $P_{2}$, stent versus no stent; $P_{0}$, interaction between diabetes and stent. 
Table 6 Comparison of clinical complications and event-free survival

\begin{tabular}{|c|c|c|c|c|c|}
\hline & $\begin{array}{l}Y+\text { nondiabetic } \\
(n=256)\end{array}$ & $\begin{array}{l}\text { O + nondiabetic } \\
(n=227)\end{array}$ & $\begin{array}{l}Y+\text { diabetic } \\
(n=|| 3)\end{array}$ & $\begin{array}{l}\text { O + diabetic } \\
(n=137)\end{array}$ & $P$-value \\
\hline Acute HF, n (\%) & $7(2.7)$ & $26(11.5)^{*}$ & $8(7.1)$ & $27(19.7)^{*, \#, \Delta}$ & 0.000 \\
\hline Death, n (\%) & $6(2.3)$ & $13(5.7)$ & $2(1.8)$ & $6(4.4)$ & 0.150 \\
\hline $\mathrm{AA}, \mathrm{n}(\%)$ & I $(0.4)$ & $15(6.6)^{*}$ & $3(2.7)$ & $9(6.6)^{*}$ & 0.001 \\
\hline VA, n (\%) & $12(4.7)$ & $21(9.3)$ & $2(1.8)^{\#}$ & $14(10.2)^{\Delta}$ & 0.011 \\
\hline Twice vascular reconstruction, $\mathrm{n}(\%)$ & $20(7.8)$ & $10(4.4)$ & $12(10.6)^{\#}$ & $3(2.2)^{*, \Delta}$ & 0.018 \\
\hline Rescue, n (\%) & $7(2.7)$ & $14(6.2)$ & $4(3.5)$ & $5(3.6)$ & 0.278 \\
\hline Event-free survival, n (\%) & $236(92.2)$ & $20 \mathrm{I}(88.5)$ & I0I (89.4) & $110(80.3)^{* \#}$ & 0.006 \\
\hline
\end{tabular}

Notes: Group $Y$, aged $<65$ years; group $O$, aged $\geq 65$ years. ${ }^{*} P<0.05$ versus $Y+$ no diabetes; ${ }^{\sharp} P<0.05$ versus $O+$ no diabetes; ${ }^{\Delta P}<0.05$ versus $Y+$ diabetes.

Abbreviations: $\mathrm{AA}$, atrial arrhythmia; $\mathrm{HF}$, heart failure; $\mathrm{VA}$, ventricular arrhythmia.

Table 2). Total costs, treatment costs, laboratory testing fees, consultation fees, and bed fees were lower in older nondiabetic patients than in younger nondiabetic patients $(P<0.05)$, and the mean hospital stay was shorter for older nondiabetics than for younger nondiabetics $(P<0.05)$. Older diabetic patients incurred lower total costs, treatment costs, laboratory testing fees, consultation fees, and bed fees than younger diabetic patients $(P<0.05)$, and the mean hospital stay was shorter for older diabetics than for younger diabetics $(P<0.05)$. There was no difference in total costs, treatment costs, total drug costs, inspection fees, bed fees, nursing fees, or hospital stay between older diabetics and older nondiabetics $(P>0.05)$. There was also no difference in total costs, treatment costs, total drug costs, inspection fees, bed fees, nursing fees, or hospital stay between younger diabetics and younger nondiabetics $(P>0.05)$. In older patients, laboratory testing fees were higher for diabetics than for nondiabetics $(P<0.05)$. In addition, older patients with diabetes incurred lower total costs, treatment costs, total drug costs, inspection fees, consultation fees, and bed fees than younger patients without diabetes $(P<0.05)$, and mean hospital stay was shorter for older diabetics than for younger diabetics $(P<0.05$, Table 3$)$.

Multivariate linear regression showed that stenting ( $\beta=0.685, P=0.000)$, white cell count $(\beta=0.152, P=0.000)$, secondary revascularization $(\beta=0.130, P=0.003)$, atrial arrhythmia ( $\beta=0.116, P=0.006)$, and body weight $(\beta=0.109$, $P=0.011)$ were factors affecting total costs in older patients with acute MI. Stenting ( $\beta=0.508, P=0.000$ ), fibrinogen ( $\beta=0.176, P=0.000)$, and secondary revascularization ( $\beta=0.145, P=0.002)$ were factors affecting treatment costs in older patients. Stenting was the most important factor affecting total hospitalization costs and treatment costs. The presence of a stent increased total hospitalization costs by 0.685 units and treatment costs by 0.508 units (Table 4 ). In the univariate general linear model, diabetes did not have an impact on hospitalization costs or duration of hospital stay in older patients with acute MI, whereas stenting was an important factor affecting hospitalization costs and hospital stay. In addition, diabetes and stent are not interaction terms in affecting the hospitalization costs and hospital stay of older patients with acute MI (Table 5).

The incidence of acute HF was higher in older inpatients than in younger inpatients from the diabetic group $(19.7 \%$ versus $7.1 \%, P<0.05)$ and nondiabetic group $(11.5 \%$ versus $2.7 \%, P<0.05)$. The incidence of acute HF was higher in older diabetic inpatients than in their nondiabetic counterparts $(19.7 \%$ versus $11.5 \%, P<0.05)$, as was event-free survival $(80.3 \%$ versus $88.5 \%, P<0.05)$. In addition, event-free survival of younger inpatients without diabetes was higher than in older inpatients with diabetes $(92.2 \%$ versus $80.3 \%$,

Table 7 Influence of stenting on the incidence of hospital events and event-free survival

\begin{tabular}{|c|c|c|c|c|c|c|c|c|c|c|c|c|}
\hline & \multicolumn{2}{|c|}{$\begin{array}{l}Y+\text { nondiabetic } \\
(\mathrm{n}=256)\end{array}$} & \multirow[t]{2}{*}{$P_{1}$} & \multicolumn{2}{|c|}{$\begin{array}{l}\text { O + nondiabetic } \\
(n=227)\end{array}$} & \multirow[t]{2}{*}{$P_{2}$} & \multicolumn{2}{|c|}{$\begin{array}{l}Y \text { + diabetic } \\
(n=|| 3)\end{array}$} & \multirow[t]{2}{*}{$P_{3}$} & \multicolumn{2}{|c|}{$\begin{array}{l}\text { O + diabetic } \\
(n=\mid 37)\end{array}$} & \multirow[t]{2}{*}{$P_{4}$} \\
\hline & $\begin{array}{l}\text { No stent } \\
(n=45)\end{array}$ & $\begin{array}{l}\text { Stent } \\
(n=2 I I)\end{array}$ & & $\begin{array}{l}\text { No stent } \\
(n=|2|)\end{array}$ & $\begin{array}{l}\text { Stent } \\
(n=106)\end{array}$ & & $\begin{array}{l}\text { No stent } \\
(n=39)\end{array}$ & $\begin{array}{l}\text { Stent } \\
(n=74)\end{array}$ & & $\begin{array}{l}\text { No stent } \\
(n=90)\end{array}$ & $\begin{array}{l}\text { Stent } \\
(n=47)\end{array}$ & \\
\hline AHF, n (\%) & $2(4.4)$ & $5(2.4)$ & 0.356 & $22(18.2)$ & $4(3.8)$ & 0.001 & $5(12.8)$ & $3(4.1)$ & 0.122 & $25(27.8)$ & $2(4.3)$ & 0.001 \\
\hline Death, n (\%) & $3(6.7)$ & $3(1.4)$ & 0.069 & II (9.I) & $2(1.9)$ & 0.022 & I (2.6) & I (I.4) & 1.000 & 6 & 0 & 0.094 \\
\hline $\mathrm{AA}, \mathrm{n}(\%)$ & 0 & I & 1.000 & $8(6.6)$ & $7(6.6)$ & 1.000 & I (2.6) & $2(2.7)$ & 1.000 & $6(6.7)$ & $3(6.4)$ & 1.000 \\
\hline VA, n (\%) & $2(4.4)$ & $10(4.7)$ & 1.000 & $13(10.7)$ & $8(7.5)$ & 0.494 & 0 & 2 & 0.544 & $10(11.1)$ & $4(8.5)$ & 0.77 I \\
\hline $\begin{array}{l}\text { Event-free } \\
\text { survival, } \mathrm{n}(\%)\end{array}$ & $42(93.3)$ & I9I (90.5) & 0.775 & $99(81.8)$ & $96(90.6)$ & 0.084 & $34(87.2)$ & $62(83.8)$ & 0.784 & $65(72.2)$ & 43 (9I.5) & 0.008 \\
\hline
\end{tabular}

Notes: Group $Y$, aged $<65$ years; group $O$, aged $\geq 65$ years. $P_{1}$, stent versus no stent in younger nondiabetics; $P_{2}$, stent versus no stent in older nondiabetics; $P_{3}$, stent versus no stent in younger diabetics; $P_{4}$, stent versus no stent in older diabetics.

Abbreviations: AHF, acute heart failure; $A A$, atrial arrhythmia; VA, ventricular arrhythmia. 
Table 8 Binary logistic regression model of factors affecting acute heart failure in older patients with acute myocardial infarction

\begin{tabular}{lllll}
\hline & $\boldsymbol{\beta}$ & P-value & OR & 95\% Cl \\
\hline HR (per minute) & 0.044 & 0.000 & 1.045 & $1.020-1.072$ \\
UA $(\mu \mathrm{mol} / \mathrm{L})$ & 0.006 & 0.003 & 1.006 & $1.002-1.009$ \\
Stent $(\mathrm{Y} / \mathrm{N})$ & -1.667 & 0.005 & 0.189 & $0.059-0.602$ \\
Weight $(\mathrm{kg})$ & -0.044 & 0.038 & 0.957 & $0.918-0.998$ \\
\hline
\end{tabular}

Abbreviations: $\mathrm{HR}$, heart rate; $\mathrm{Cl}$, confidence interval; $\mathrm{OR}$, odds ratio; $\mathrm{UA}$, uric acid.

$P<0.05)$. For nondiabetic inpatients, the incidence of atrial arrhythmia was higher in the older group than in the younger group $(P<0.05)$. For diabetic inpatients, the incidence of ventricular arrhythmia was higher in the older group than in the younger group $(P<0.05)$, but the incidence of secondary revascularization was lower $(P<0.05$, Table 6$)$.

In the older age group, PCI decreased the incidence of acute $\mathrm{HF}$ in both diabetics $(27.8 \%$ versus $4.3 \%, P=0.001)$ and nondiabetics $(18.2 \%$ versus $3.8 \%, P=0.001)$, and decreased mortality in older inpatients without diabetes $(9.1 \%$ versus $1.9 \%, P=0.022$ ). PCI also increased the event-free survival rate in older inpatients with diabetes $(72.2 \%$ versus $91.5 \%$, $P=0.008$, Table 7).

Binary logistic regression showed stenting (odds ratio 0.189, 95\% confidence interval $[\mathrm{CI}] 0.059-0.602, P=0.005)$ and body weight (odds ratio $0.957,95 \%$ CI $0.918-0.998, P=0.038$ ) to protect against acute HF in older patients with acute MI. Heart rate (odds ratio $1.045,95 \% \mathrm{CI} 1.020-1.072, P=0.000$ ) and uric acid (odds ratio 1.006, 95\% CI 1.002-1.009, $P=0.003$ ) were risk factors for acute HF in older patients with acute MI (Table 8).

\section{Analysis of cost-effectiveness}

When the CER was calculated based on average total costs for older patients with acute MI, the inhospital incidence of acute

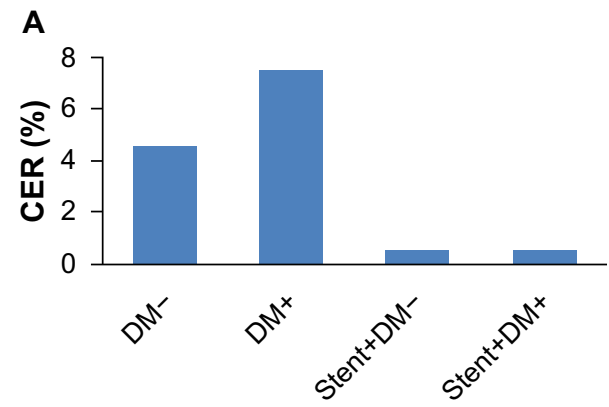

CER was calculated based on the average total costs
HF after implementing PCI was lower in diabetics $(0.53 \%$ versus $7.51 \%)$ and nondiabetics $(0.47 \%$ versus $4.55 \%)$ than when PCI was not performed. When the CER was calculated based on average treatment costs, the inhospital incidence of acute HF after implementing PCI was also lower in diabetics $(1.43 \%$ versus $4.96 \%)$ and nondiabetics $(1.00 \%$ versus $2.94 \%$ ) than when PCI was not performed (Figure 1).

For older patients with acute MI, the ICER estimate for implementing PCI was higher in diabetics than in nondiabetics when ICER was calculated based on average total costs $(-5.30 \%$ versus $-3.50 \%)$ and average treatment costs $(-9.60 \%$ versus $-4.50 \%)$ from the perspective of reduction in inpatient incidence of acute HF after implementing PCI (Figure 2).

\section{Discussion}

The main findings of our study are that older patients incurred lower total costs and treatment costs than their younger counterparts and that diabetes does not have an impact on hospitalization costs for patients with acute MI. Stenting is an important factor affecting hospitalization costs in older patients. Implementation of PCI can reduce the incidence of acute HF in older inpatients with acute MI, but not in younger ones.

In this study, older patients incurred lower total costs and treatment costs than younger patients, and the hospital stay was shorter for older patients than for younger patients, independent of diabetes status. For older patients, stenting was a more important factor affecting hospitalization costs than diabetes. Moreover, there was no relationship between diabetes and stenting with regard to hospitalization costs or duration of hospital stay in older patients with acute MI.

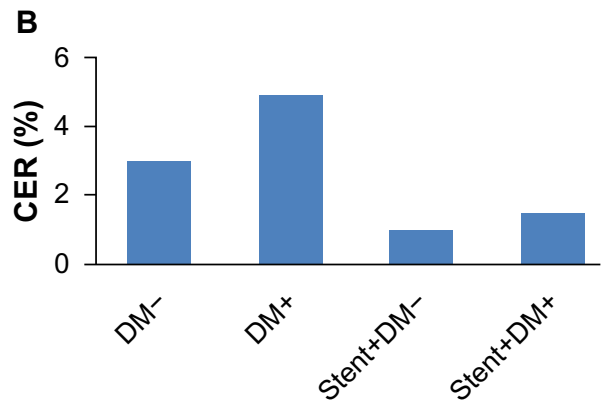

CER was calculated based on the
average treatment costs

Figure I Cost-effectiveness ratio was calculated from the perspective of reduction in the in hospital incidence of acute heart failure in older patients with acute myocardial infarction after implementing percutaneous coronary intervention.

Notes: DM-, nondiabetic; DM+, diabetic. (A) CER was calculated based on the average total costs; (B) CER was calculated based on the average treatment costs. Abbreviations: DM, diabetes mellitus; CER, cost-effectiveness ratio. 

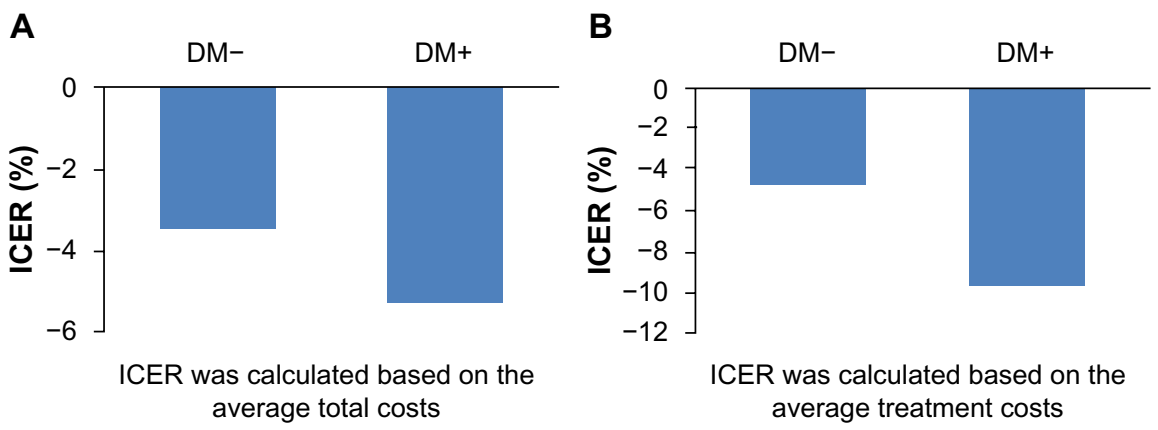

Figure 2 Incremental cost-effectiveness ratio (ICER) was calculated from the perspective of reduction in the inhospital incidence of acute heart failure in older patients with acute myocardial infarction after implementing percutaneous coronary intervention.

Notes: DM-, nondiabetic; DM+, diabetic. (A) ICER was calculated based on the average total costs; (B) ICER was calculated based on the average treatment costs. Abbreviation: DM, diabetes mellitus.

The incidence of acute HF decreased with increasing total costs and treatment costs in inpatients with acute MI. The incidence of acute HF was higher in older inpatients than in younger inpatients, but their hospitalization costs were lower. While diabetes was associated with an increased incidence of acute HF in older inpatients, it did not have an impact on hospitalization costs. It has been reported previously that age is a major independent predictor of $\mathrm{HF}$ after acute $\mathrm{MI}^{31}$ and that diabetes mellitus is associated with the development of diastolic heart failure, ${ }^{32}$ and our results are in accordance with these reports. In addition, inpatient event-free survival increased as total costs and treatment costs increased. Although older patients incurred lower hospitalization costs than younger patients, there was no difference between older and younger inpatients with regard to event-free survival. The presence of diabetes decreased event-free survival in older inpatients, but had no impact on hospitalization costs.

PCI is one of the most powerful predictors of improved outcome in patients with acute coronary syndrome. ${ }^{33,34}$ The results of our study suggest that, in elderly inpatients, PCI can reduce the risk of acute HF, decrease mortality in those without diabetes, and increase the event-free survival rate in those with diabetes. Our cost-effectiveness analysis shows that the ICER estimate for implementing PCI is higher in diabetics than in nondiabetics from the perspective of decreasing the incidence of acute HF in inpatients, but only for the elderly, ie, implementation of PCI after acute MI in older diabetics is more cost-effective than in nondiabetics.

In conclusion, implementation of PCI in older inpatients can reduce their risk of acute $\mathrm{HF}$ and increase their likelihood of event-free survival. Although PCI clearly increases the hospitalization costs, it is relatively more cost-effective in older patients with acute MI. Moreover, older patients with acute MI and diabetes mellitus benefit more from PCI than those with acute MI and without diabetes mellitus.
Our study has several limitations. First, it was retrospective in nature and we could not determine the long-term impact of type 2 diabetes in older patients with acute MI. Second, it did not include patients who had undergone coronary artery bypass grafting, so we could not compare its benefits relative to those of PCI. Third, it was a singlecenter study, and the possibility of bias arising from this cannot be excluded.

\section{Acknowledgments}

This work was supported by research grants from the National Basic Research Program of China (973 Program, 2013CB530700), the National Natural Science Foundation of China (81070192, 81070141, 81100605, 81270352, 81270287), the Natural Science Foundation of Shandong Province (BS2013YY017), the Independent Innovation Foundation of Shandong University (2012JC034), and the Cardiovascular Exploration Research Foundation of the Chinese Medical Doctors Association (DFCMDA201320).

\section{Disclosure}

The authors report no competing interests in this work.

\section{References}

1. Zhang NJ, Guo M, Zheng X. China: awakening giant developing solutions to population aging. Gerontologist. 2012;52(5):589-596.

2. Dong B, Ding Q. Aging in China: a challenge or an opportunity? J Am Med Dir Assoc. 2009;10(7):456-458.

3. Aounallah Skhiri H, Ben Abdelkrim I, Ouldezein H, et al. The cost of acute myocardial infarction management: the Tunisian experience. Tunis Med. 2005;83 Suppl 5:24-29.

4. Heerey A, McGowan B, Ryan M, Walsh M, Feely J, Barry M. Cost of treating acute myocardial infarction in an Irish teaching hospital. Ir Med J. 2001;94(5):144-146.

5. Maniadakis N, Kaitelidou D, Siskou O, et al. Economic evaluation of treatment strategies for patients suffering acute myocardial infarction in Greece. Hellenic J Cardiol. 2005;46(3):212-221.

6. Zeng HK, Fang M, Ye H, et al. [Influence of different treatment patterns on cost-effectiveness in treatment of acute myocardial infarction] Zhonghua Yi Xue Za Zhi. 2008;88(20):1398-1401. Chinese. 
7. Rask Madsen C, Jensen G, Kober L, et al. Agerelated mortality, clinical heart failure, and ventricular fibrillation in 4259 Danish patients after acute myocardial infarction. Eur Heart J. 1997;18(9):1426-1431.

8. Gurwitz JH, Col NF, Avorn J. The exclusion of the elderly and women from clinical trials in acute myocardial infarction. JAMA. 1992;268(11):1417-1422.

9. Tu JV, Nardi L, Fang J, Liu J, Khalid L, Johansen H; the Canadian Cardiovascular Outcomes Research Team. National trends in rates of death and hospital admissions related to acute myocardial infarction, heart failure and stroke, 1994-2004. Can Med Assoc J. 2009;180(13): E118-E125.

10. Cowie CC, Rust KF, Ford ES, et al. Full accounting of diabetes and prediabetes in the US population in 1988-1994 and 2005-2006. Diabetes Care. 2009;32(2):287-294.

11. Ogden CL, Carroll MD, Curtin LR, McDowell MA, Tabak CJ, Flegal KM. Prevalence of overweight and obesity in the United States, 1999-2004. JAMA. 2006;295(13):1549-1555.

12. Maruthur NM. The growing prevalence of type 2 diabetes: increased incidence or improved survival? Curr Diab Rep. 2013;13(6):786-794.

13. Peng XR, Zhao YF, Zou DJ, Gu P. [The role of diabetes mellitus as a risk factor of acute myocardial infarction]. Zhongguo Wei Zhong Bing Ji Jiи Yi Xие. 2011;23(6):322-328. Chinese.

14. Centers for Disease Control and Prevention. National Diabetes Fact Sheet: General Information and National Estimates on Diabetes in the United States, 2007. Atlanta, GA, USA: US Department of Health and Human Services, Centers for Disease Control and Prevention; 2008.

15. Melchior T, Kober L, Madsen CR, et al. Accelerating impact of diabetes mellitus on mortality in the years following an acute myocardial infarction. Eur Heart J. 1999;20(13):973-978.

16. Zuanetti G, Latini R, Maggioni AP, Santoro L, Franzosi MG. Influence of diabetes on mortality in acute myocardial infarction: data from the GISSI-2 study. J Am Coll Cardiol. 1993;22(7):1788-1794.

17. Aguilar D, Solomon SD, Kober L, et al. Newly diagnosed and previously known diabetes mellitus and 1-year outcomes of acute myocardial infarction: the Valsartan In Acute Myocardial Infarction (VALIANT) Trial. Circulation. 2004;110(12):1572-1578.

18. Fang J, Alderman MH. Impact of the increasing burden of diabetes on acute myocardial infarction in New York City: 1990-2000. Diabetes. 2006;55(3):768-773.

19. Lopez-de-Andres A, Hernández-Barrera V, Carrasco-Garrido P, Esteban-Hernandez J, Gil-de-Miguel A, Jiménez-García R. Trends of hospitalizations, fatality rate and costs for acute myocardial infarction among Spanish diabetic adults, 2001-2006. BMC Health Serv Res. 2010;10:59.

20. Ovbiagele B, Markovic D, Fonarow GC. Recent US patterns and predictors of prevalent diabetes among acute myocardial infarction patients. Cardiol Res Pract. 2011;2011:145615.
21. Gabriel R, Alonso M, Segura A, et al. Prevalence, geographic distribution and geographic variability of major cardiovascular risk factors in Spain. Pooled analysis of data from population-based epidemiological studies: the ERICE Study. Rev Esp Cardiol. 2008;61(10):1030-1040.

22. Cheng YJ, Imperatore G, Geiss LS, et al. Secular changes in the agespecific prevalence of diabetes among US Adults: 1988-2010. Diabetes Care. 2013;36(9):2690-2696.

23. Qiao Q, Hu G, Tuomilehto J, et al. Age- and sex-specific prevalence of diabetes and impaired glucose regulation in 11 Asian cohorts. Diabetes Care. 2003;26(6):1770-1780.

24. Bakler T, Baburin A, Teesalu R, Rahu M. Comparison of management and 30-day mortality of acute myocardial infarction in men versus women in Estonia. Acta Cardiol. 2004;59(3):275-281.

25. McCormick D, Gurwitz JH, Lessard D, Yarzebski J, Gore JM, Goldberg RJ. Use of aspirin, $\beta$-blockers, and lipid-lowering medications before recurrent acute myocardial infarction: missed opportunities for prevention? Arch Intern Med. 1999;159(6):561-567.

26. Woon VC, Lim KH. Acute myocardial infarction in the elderly the differences compared with the young. Singapore Med J. 2003;44(8): 414-418.

27. de Boer MJ, Ottervanger JP, Suryapranata H, et al. Old age and outcome after primary angioplasty for acute myocardial infarction. J Am Geriatr Soc. 2010;58(5):867-872.

28. Nicolau JC, Serrano CV Jr, Giraldez RR, et al. In patients with acute myocardial infarction, the impact of hyperglycemia as a risk factor for mortality is not homogeneous across age-groups. Diabetes Care. 2012;35(1):150-152.

29. Hsu LF, Mak KH, Lau KW, et al. Clinical outcomes of patients with diabetes mellitus and acute myocardial infarction treated with primary angioplasty or fibrinolysis. Heart. 2002;88(3):260-265.

30. Carral F, Aguilar M, Olveira G, Mangas A, Doménech I, Torres I. Increased hospital expenditures in diabetic patients hospitalized for cardiovascular diseases. J Diabetes Complications. 2003;17(6): 331-336.

31. Bershteĭn LL, Novikov VI, Grishkin IuN. [Advanced age as a risk factor for heart failure after acute myocardial infarction]. Adv Gerontol. 2008;21(2):265-269. Russian.

32. Araszkiewicz A, Janus M, Prech M, et al. [Relations of diabetes mellitus, microvascular reperfusion and left ventricular remodeling in patients with acute myocardial infarction treated with primary coronary intervention]. Kardiol Pol. 2014;72(1):20-26. Polish.

33. Bauer T, Koeth $\mathrm{O}$, Jünger $\mathrm{C}$, et al. Effect of an invasive strategy on in-hospital outcome in elderly patients with non-ST-elevation myocardial infarction. Eur Heart J. 2007;28(23):2873-2878.

34. Newell MC, Henry JT, Henry TD, et al. Impact of age on treatment and outcomes in ST elevation myocardial infarction. Am Heart $J$. 2011;161(4):664-672.
Clinical Interventions in Aging

\section{Publish your work in this journal}

Clinical Interventions in Aging is an international, peer-reviewed journal focusing on evidence-based reports on the value or lack thereof of treatments intended to prevent or delay the onset of maladaptive correlates of aging in human beings. This journal is indexed on PubMed Central, MedLine, the American Chemical Society's 'Chemical Abstracts Ser-

\section{Dovepress}

vice' (CAS), Scopus and the Elsevier Bibliographic databases. The manuscript management system is completely online and includes a very quick and fair peer-review system, which is all easy to use. Visit http://www.dovepress.com/testimonials.php to read real quotes from published authors. 